\title{
Near infrared spectroscopic measurement of strain in rocks
}

Emily Butcher, Andrew Gibson, Philip M Benson, Nick Koor \& Gareth Swift

Rock Mechanics Laboratory, School of Earth and Environmental Sciences, University of Portsmouth, Burnaby Building, Burnaby Road, Portsmouth. PO1 3QL. United Kingdom.

Corresponding Author - Emily Butcher (emily.butcher@port.ac.uk)

\begin{abstract}
The measurement of strain is a fundamental and widely studied parameter in engineering, rock mechanics, construction and materials testing. Contact sensors often used in these fields require contact with the target surface throughout the duration of a strain event. Non-contact methods typically require that that the measurement surface is prepared and often coated prior to testing. This paper considers the potential application of near infrared spectroscopy as a non-contact technique for the measurement of strain on natural surfaces. Excellent correlation was found between surface measurements of visible-NIR spectra and longitudinal strain taken during indirect Brazilian Disc Test for samples of sandstone, marble and basalt.
\end{abstract}

\section{Keywords}

Strain measurement, near infrared spectroscopy; Indirect Tensile Strength, rock

\section{Introduction: Principles and Methodology of Strain Measurements}

The measurement of strain in rocks is important in many fields of engineering and applied geoscience. Laboratory measurements of strain enable the derivation of parameters such as Young's Modulus and Poisson's Ratio, which are important inputs to geotechnical design. Field applications where the accurate determination of rock strain is important include the monitoring of natural and man-made slopes ${ }^{1-3}$, tunnels ${ }^{4}$, mine stability ${ }^{5}$, accumulation of tectonic strains at faults ${ }^{6}$ and changes to volcanic systems ${ }^{7}$. Techniques to measure rock strain can be classified as those which require contact with the rock surface and those which can be considered non-contact (remote).

Contact techniques normally involve either electrical strain gauges (ESG) or Fiber Bragg Gratings (FBG). Electrical strain gauges consist of electrical contacts that are bonded to the target surface ${ }^{8}$. Changes in electrical resistance allows the changing strain to be derived via a simple calibration. The technique is technologically simple, low cost and has found wide application. Fiber Bragg Gratings 
consist of an optical fibre with a grating etched at known locations along the fibre. Any deformation of the grating caused by surface deformation or a change in temperature causes a shift in reflection at a Bragg wavelength which can be calibrated against the grating configuration ${ }^{9-11}$. FBG gauges have been successfully applied to monitor the structural health of civil infrastructure including mine networks ${ }^{12}$, roads ${ }^{13}$ and tunnels ${ }^{14,15}$. However contact gauges can only measure the strain accumulated around a small area and the results become less accurate at high strain rates ${ }^{16}$. Because they are bonded with the target, they cannot be removed from the measurement surface, and are therefore single use only, making them susceptible to degradation over long periods of time.

Remote techniques include digital image correlation (DIC) ${ }^{17}$, laser speckle correlation (LSC) and electronic speckle pattern interferometry $(\mathrm{ESPI})^{18,19}$. In each, strain is calculated by comparing features in images generated before and after displacement, often utilising features in a random pattern, either naturally or artificially applied. DIC methods are fairly simple to set up, can require relatively little sample preparation, and can be used both in laboratory and field environments at a range of measurement resolutions (sub-micron to centimetre) ${ }^{20}$. DIC has been used to measure strain in natural rock ${ }^{21,22}$ and concrete ${ }^{23}$. It has been demonstrated that DIC could be a useful method to understand the propagation of cracking during rock strain testing of homogenous materials ${ }^{24,25}$. However, the technique relies upon the ability to define a Region Of Interest, (ROI) that can be observed consistently at different measurement epochs and from which movement patterns can be compared ${ }^{26}$. LSC or ESPI use a laser to illuminate a target surface. Reflected light passes through a beam splitter which may be an interferometer, an image shearing camera or prism $^{27}$. Images are projected together onto a receiving camera/charged couple device (CCD), with the speckle pattern resulting from the deformed and un-deformed surfaces superimposed. The change (difference) due to strain is then derived from the comparison between the pattern resulting from the reflection of the original beam and that of the target surface. ESPI involves little or no sample preparation, and can generate strain measurements down to the micron scale ${ }^{28}$, though the interpretation of imagery can be complex ${ }^{29}$.

The usefulness of near infrared (NIR) spectroscopy as not just an identification tool but also a diagnostic tool has grown exponentially over the past few years. Although applying NIR spectroscopy to detect changes within a sample is not a new concept, the application to rock samples is innovative and timely. In fact NIR has been used as a non-destructive method to evaluate mechanical properties in wood ${ }^{30}$, flax fibres ${ }^{31}$ and rubber ${ }^{32}$. It has also been used to evaluate the change in shape of rubber latex during swelling ${ }^{33}$. 


\section{Near infrared Spectroscopy and the measurement of rock strain}

The use of NIR spectroscopy in the earth sciences is well established, if not widely practised. Though spectra are not typically diagnostic of geological surfaces, signatures are often compared to known library samples ${ }^{34,35}$ or calibration tests ${ }^{36}$. The technique has been used effectively to evaluate many properties such as particle size, clay mineralogy ${ }^{37}$, bulk mineralogy ${ }^{38}$, moisture content ${ }^{39}$, organic content $^{40}$, contamination ${ }^{41,42}$, weathering ${ }^{43}$ or a combination of several of these factors ${ }^{44}$. Industrial application is primarily mineral exploration ${ }^{45-47}$, but NIR has also been used to assess masonry ${ }^{48}$ and surface degradation of asbestos ${ }^{49}$, for example. The value of the technique to remotely evaluate rock composition and rock properties in the field of planetary sciences has also been investigated ${ }^{50}$

However, there are relatively few reports systematically investigating the use of infrared techniques for the measurement of strain. One such study reports how infrared light may be used to examine the strength of isolated quartz crystals under high pressure and high temperature (1.64 GPa and 800 $\left.{ }^{\circ} \mathrm{C}\right)^{51}$. The spectral measurements were performed using an Infrared beam and detector measuring between $2500 \mathrm{~nm}$ and $4000 \mathrm{~nm}$. They found that the Infrared absorption spectrum of quartz containing hydroxide $(\mathrm{OH})$ may be separated into two parts - a broad structureless band from 2940 $\mathrm{nm}$ to $3570 \mathrm{~nm}$, and a series of sharp peaks between $2700 \mathrm{~nm}$ and $3030 \mathrm{~nm}$. Quartz crystals with an increase in absorption within the broad band range correlated directly with a decrease in strength.

In this paper, we report new data that demonstrates how NIR spectroscopy may complement conventional techniques for the measurement of strain in rocks, possessing the advantages that no sample contact is required and that measurement and interpretation is relatively simple. Further to this, the nature of the measurement may provide fundamental information on sample behaviour that is not present in measurements derived from other techniques. Previous work has shown NIR to be an effective method for strain measurement in the laboratory on simple rock samples of basalt ${ }^{52}$. This paper presents results of a new and extended series of laboratory experiments designed to test whether NIR spectroscopy can be applied to strain measurement in other rock types.

\section{Materials and methods}

\section{Sample Preparation}

Four samples of three different rock types were used to represent a broad range of geological materials; an orange, granular sedimentary Darley Dale sandstone; a crystalline metamorphic yellowish white Bianco Carrara Marble, and a dark grey, crystalline igneous Basalt taken from Mt Etna, Sicily. All the samples were cut from blocks with no visible fractures or evidence of structural 
deformations, defects or weathering (Figure 1a). The four samples of each rock type were cored using a diamond-tipped core barrel with a diameter of $40 \mathrm{~mm}(+/-0.20 \mathrm{~mm}$ ) (Figure $1 \mathrm{~b})$. The cores were cut into discs $18 \mathrm{~mm}$ thick and finally ground with silicon carbide grit on a rotary platform to ensure a flat surface. For the purpose of this experiment, each face was inspected and samples possessing any obvious inhomogeneity such as mineral veins, or differing grain/crystal sizes were rejected. All samples were oven dried at $40^{\circ} \mathrm{C}$ for 24 hours prior to testing and compliant with the requirements for subsequent mechanical testing to the standards of the International Society for Rock Mechanics ${ }^{53}$.

[Insert Figure $1 \mathrm{a} / \mathrm{b}$ ]

\section{Measurement of NIR Spectra during Strain Testing}

The testing described here combines results from an internationally recognised test for measurement of rock deformation/strength and the concurrent measurement of NIR spectra using a conventional spectrometer. The rock test chosen was a modified version of the internationally accepted method to determine the tensile strength of rocks, the Indirect Brazilian Tensile Test (IBT) $)^{53}$. In this test, standard disc samples were placed vertically in a circular incompressible steel rig. The sample was in contact with the rig only at the top and bottom of the specimen so that the sides of the sample were unrestrained. A vertical load was applied and increased at a strain rate of $5 \times 10^{-5} \mathrm{~s}^{-1}$ until the rock sample failed due to lateral (tensile) expansion. Knowledge of the change in vertical height of the sample at the point of maximum load before failure was used to calculate strain in the direction of loading. Importantly, this procedure allowed an unobstructed view to the flat disc surface parallel with the axis of longitudinal shortening for the duration of the test, which was used to measure surface reflectance.

Samples were mounted in a standard tensile curved-jaw loading jig and force was applied using an Instron 600LX load frame and data logger (Instron, Norwood, MA). An initial load of $100 \mathrm{~N}$ was applied to ensure the platens of the jig were in contact with the sample and that the sample was held firmly. Thereafter, the load upon the sample was increased incrementally to produce a vertical change in height (strain) of $0.05 \%$ as calculated from an extensometer within the load frame. Increments were continued until the sample failed by the formation of vertical crack across the diameter of the disc. For the purpose of this test, strain was defined by the change in diametrical height of the tensile disc divided by its original height (Figure 2 and Equation 1). At each strain 
increment, the loading was held for approximately 10 seconds to enable the capture of an NIR spectra of the free rock surface. Spectra were captured using an Analytical Spectral Devices (ASD) Labspec 5000 spectrometer (Malvern Panalytical ASD, Boulder, CO) that had a spectral resolution of 3nm @ 700nm and 10nm @ 1400/2100. The spectrometer was used with a 25 mm diameter circular 'Hi-Bright' fore-optic with $1 \mathrm{~m}$ jumper fibre. The fore-optic, which contained an internal light source, was placed directly against the centre surface of the rock sample for the duration of the IBT test (Figure 3), with measurements taken at each strain increment. Each scan in the range $350-2500 \mathrm{~nm}$ took approximately 10 seconds, during which 50 full-width radiance scans were taken and averaged. Radiance measurements were converted to absolute reflectance by comparison with reference measurements periodically taken of a Spectralon panel.

[Insert Figure 2]

$$
\% \operatorname{Strain}(\varepsilon)=\left(\Delta h / H_{o}\right) \times 100 \quad \text { Equation } 1
$$

[Insert Figure 3]

\section{Results and Discussion}

The range of results from the indirect tensile strength test for each rock type are shown in figure 4. Etna Basalt has the highest tensile strength of $8.45 \mathrm{MPa}$ (mean 7.68MPa). Darley Dale sandstone was the weakest material with a maximum strength of $4.25 \mathrm{MPa}$ (mean 3.79MPa). Carrara Marble was intermediate in terms of tensile strength with a maximum of 6.24MPa (mean 5.68MPa). These results are consistent with characteristics expected for each rock type.

[Insert Figure 4]

Example reflectance spectra of each rock type prior to loading are shown in Figure 5. Reflectance of the Darley Dale sandstone is typical of a yellow red sandstone with a broad convex spectral 'continuum' upon which are superimposed sharp absorption features around 1400, 1870 and 2200 $\mathrm{nm}$ normally associated with the presence of water bound in clay particles ${ }^{54,55}$. The sample also 
displays a broad absorption 800-1350 $\mathrm{nm}$ which is typical of reddish brown rocks containing iron oxide $^{55,56}$. The Carrara Marble spectrum is typical of a pale coloured marble ${ }^{57}$, showing a broad reduction in reflectance 350-2500 $\mathrm{nm}$ with sharp absorptions at 1850 and $2150 \mathrm{~nm}$ and two twinned absorptions at 1950 and $2350 \mathrm{~nm}^{55,58}$. Etna Basalt demonstrates low reflectance across all wavelengths as would be expected of a dark rock ${ }^{50}$, although there is a broad concave feature at $1050 \mathrm{~nm}$.

[Insert Figure 5]

\section{Analyses}

Reflectance spectra of each rock type were analysed to identify a common wavelength or group of wavelengths that showed consistent variation with increasing strain. Although this process is usually achieved by linear or partial least squares regression, visual inspection is useful when comparing homogeneous samples of different materials. Regressions between strain and reflectance at specific wavelengths were carried out to determine a statistical relationship.

Carrara Marble samples (CM1-4) show a clear relationship between strain and reflectance at $2050 \mathrm{~nm}$ (Figure 6). The reflectance decreases with increasing strain for all four samples. Whilst CM1 is almost linear, the general pattern is 'best fit' with a simple polynomial yielding with $R^{2}$ between 0.994 and 0997. Results from the Darley Dale Sandstone samples (DD1-4) showed a positive correlation between strain and reflectance at $1970 \mathrm{~nm}$ (Figure 7). Polynomial regression was applied to the data with $R^{2}$ ranging between 0.980 and 0.995 . The lower overall reflectance (albedo) of the Etna Basalt (EB1-4) meant it was not possible to determine a single wavelength that showed a consistent pattern with increasing strain. An average of reflectance in the range 1400-1775 nm was used (Figure 8). This shows an inverse relationship between reflectance and strain for all four Etna Basalt samples. As before, a polynomial regression was applied yielding $R^{2}$ values of $0.976-0.986$. The results therefore demonstrate a statistically significant relationship between reflectance and longitudinal strain on all rock samples. These results are significant as they indicate that it may be possible to measure strain in rock samples using NIR spectroscopy. 
The results show evidence of strong correlations between reflectance and strain however, it is difficult with this limited data set to compare the usefulness of such a measure as an analytical tool. A dimensionless relationship, here termed a Rock-Strain-Reflectance Index (RSR) was derived for each sample. This is simply the ratio of the change in reflectance between each incremental test against the original reflectance prior to the application of load ( ref $\left.^{\mathrm{n}=0}\right)$, (Equation 2).

$$
R S R=\frac{\Delta r e f^{n}}{r e f^{n=0}} \quad \text { Equation 2 }
$$

Considering the results in this way reveals the changing behaviour of the different rock types and can be used to consider what phenomena is actually being observed by the reflectance technique. Figure 9 shows that all samples demonstrate a pattern between RSR and strain and that there appears to be a consistent relationship for each rock type. There is some variance, which is expected when testing geological samples.

[Insert Figure 9]

\section{Discussion}

A plausible reason for the results obtained is that changes in surface topography/ micro-topography, which result from strain in the area of the sample under observation give rise to change in reflection from the rock surface. The granular Darley Dale Sandstone, comprising grains of sand in a cementlike matrix demonstrates an increase in reflection (RSR) with strain. Under load, these sand grains may become more tightly packed, reducing the space between grains, reducing shadow areas and creating a more consistent, specular surface and therefore a higher overall surface (albedo), a pattern often seen when soils become more densely packed. The dependency of this relationship on wavelength requires further investigation but is likely to be related to particle size distribution and by extension, the morphology of sand grain surfaces and inter-granular pores close to the RSR wavelength $(1970 \mathrm{~nm})$. It is anticipated that further experimentation using contemporaneous high resolution topographic sensing (using a blue laser will provide some further indication of whether surface changes can be responsible for the variation in surface reflectance). 
An inverse relationship between the RSR and strain is observed for the crystalline rocks tested (marble and basalt). The RSR for the Carrara Marble is derived from reflectance at an absorption feature at $2050 \mathrm{~nm}$, whereas for the Etnean Basalt (with a much lower albedo) the relationship was derived using average reflectance in the range 1400-1775 nm. Both of these samples had smooth, crystalline surfaces. Neither rock type exhibits a significant spectral absorption feature at these wavelength ranges. It is likely that the cause of the inverse relationship observed in the crystalline samples was again, a change in micro-topography. Again, although further experimentation is required the data reported here suggests that, under strain, the surface of these rocks exhibits an increase in surface roughness in magnitudes related to their RSR and therefore consistent with a corresponding reduction in reflectance, as measured in our experiments. It is not discounted that the light coloured marble may also be affected by near-surface changes which change internal reflectance related to an internal deformation at that scale.

It is important to consider the fundamental nature of the rock testing performed. The indirect tensile test exploits weaknesses in the rock matrix, placing stress upon the contact between individual rock crystals. In most rocks, the tensile strength of the matrix between grains or crystals is weaker than the grains or crystals themselves, so it is the material between crystals that ultimately fails, rather than larger crystals or grains of sand.

\section{Conclusion}

In this paper Visible - NIR spectroscopy has been applied to the measurement and understanding of rock strain in different rock types. It is concluded that for the rock types tested; marble, sandstone and basalt, there are clearly defined relationships between a reflectance index, here termed the Rock-Strain-Reflectance index (RSR) and the applied strain. There is potential for this technique to be applied to the contact and non-contact measurement of strain in rocks. Clearly, further laboratory work is required to test a wider range of materials, surfaces and illumination geometries and utilise multivariate analysis, as well as to transfer the technique into a non-contact strain gauge for industrial application. There are a wide number of laboratory tests and industrial applications where this may be of use, especially if imaging systems are utilised to capture a spatial pattern of RSR. 


\section{Acknowledgements}

The authors would like to thank James Coyne and Michelle Hale for their technical support and useful discussions.

\section{Declaration of conflicting interests}

The authors declared no potential conflicts of interest with respect to the research, authorship, and/or publication of this article.

\section{Funding}

This research received no specific grant from any funding agency in the public, commercial, or notfor-profit sectors.

\section{References}

1. Utili S, Crosta GB, Take A, et al. An integrated geophysical approach for investigating hydrogeological characteristics of a debris landslide in the Wenchuan earthquake area. Eng Geol 2017; 219: 92-106.

2. Ma K, Tang CA, Liang ZZ, et al. Stability analysis and reinforcement evaluation of high-steep rock slope by microseismic monitoring. Eng Geol 2017; 218: 22-38.

3. Stead D, Eberhardt E, Coggan JS. Developments in the characterization of complex rock slope deformation and failure using numerical modelling techniques. Eng Geol 2006; 83: 217-235.

4. Cui Y, Kishida K, Kimura M. Prevention of the ground subsidence by using the foot reinforcement side pile during the shallow overburden tunnel excavation in unconsolidated ground. Tunn Undergr Sp Technol 2017; 63: 194-204.

5. Carlà T, Farina $\mathrm{P}$, Intrieri E, et al. On the monitoring and early-warning of brittle slope failures in hard rock masses: Examples from an open-pit mine. Eng Geol 2017; 228: 71-81.

6. Dobrev ND, Košt'ák B. Monitoring tectonic movements in the Simitli Graben, SW Bulgaria. 
Eng Geol 2000; 57: 179-192.

7. Segall P. Earthquake and volcano deformation. Princeton University Press, 2010.

8. Higson G. Recent advances in strain guages. J Sci Instrum 1964; 41: 404-414.

9. Gage JR, Fratta D, Turner AL, et al. Validation and implementation of a new method for monitoring in situ strain and temperature in rock masses using fiber-optically instrumented rock strain and temperature strips. Int J Rock Mech Min Sci. Epub ahead of print 2013. DOI: 10.1016/j.ijrmms.2013.03.007.

10. Gage JR, Wang HF, Fratta $D$, et al. In situ measurements of rock mass deformability using fiber Bragg grating strain gauges. Int J Rock Mech Min Sci. Epub ahead of print 2014. DOI: 10.1016/j.jjrmms.2014.07.021.

11. Merzbacher $\mathrm{Cl}$, Kersey AD, Friebele EJ. Fiber optic sensors in concrete structures: a review. Smart Mater Struct 1996; 5: 196.

12. Chai J, Liu J, Qiu B, et al. Detecting deformations in uncompacted strata by fiber Bragg grating sensors incorporated into GFRP. Tunn Undergr Sp Technol 2011; 26: 92-99.

13. Maaskant R, Alavie T, Measures RM, et al. Fiber-optic Bragg Grating Sensors for Bridge Monitoring. Cem Concr Compos 1997; 19: 21-33.

14. Moffat R, Sotomayor J, Beltrán JF. Estimating tunnel wall displacements using a simple sensor based on a Brillouin optical time domain reflectometer apparatus. Int J Rock Mech Min Sci 2015; 75: 233-243.

15. Klar A, Dromy I, Linker R. Monitoring tunneling induced ground displacements using distributed fiber-optic sensing. Tunn Undergr Sp Technol 2014; 40: 141-150.

16. Zhang QB, Zhao J. A Review of Dynamic Experimental Techniques and Mechanical Behaviour of Rock Materials. Rock Mech Rock Eng 2014; 47: 1411-1478.

17. Pan B, Qian K, Xie H, et al. Two-dimensional digital image correlation for in-plane displacement and strain measurement: a review. Meas Sci Technol 2009; 20: 62001.

18. Yamaguchi I. A laser-speckle strain gauge. J Phys E 1981; 14: 1270.

19. la Torre IM De, del Socorro Hernández Montes M, Flores-Moreno JM, et al. Laser speckle based digital optical methods in structural mechanics: A review. Opt Lasers Eng 2016; 87: 3258. 
20. Roux S, Réthoré J, Hild F. Digital image correlation and fracture: an advanced technique for estimating stress intensity factors of 2D and 3D cracks. J Phys D Appl Phys 2009; 42: 214004.

21. Lin Q, Labuz JF. Fracture of sandstone characterized by digital image correlation. Int J Rock Mech Min Sci 2013; 60: 235-245.

22. Li D, Zhu $Q$, Zhou Z, et al. Fracture analysis of marble specimens with a hole under uniaxial compression by digital image correlation. Eng Fract Mech 2017; 183: 109-124.

23. Ramos T, Furtado A, Eslami S, et al. 2D and 3D Digital Image Correlation in Civil Engineering Measurements in a Masonry Wall. Procedia Eng 2015; 114: 215-222.

24. Abshirini M, Soltani N, Marashizadeh P. On the mode I fracture analysis of cracked Brazilian disc using a digital image correlation method. Opt Lasers Eng 2016; 78: 99-105.

25. Stirling RA, Simpson DJ, Davie CT. The application of digital image correlation to Brazilian testing of sandstone. Int J Rock Mech Min Sci 2013; 60: 1-11.

26. Sutton MA, Orteu JJ, Schreier H. Image correlation for shape, motion and deformation measurements: basic concepts, theory and applications. Springer Science \& Business Media, 2009.

27. Francis D, Tatam RP, Groves RM. Shearography technology and applications: a review. Meas Sci Technol 2010; 21: 102001.

28. Chen HHN, Su RKL, Fok SL, et al. Fracture behavior of nuclear graphite under three-point bending tests. Eng Fract Mech. Epub ahead of print 2017. DOI: https://doi.org/10.1016/j.engfracmech.2017.09.030.

29. Meda A. Tensile behaviour in natural building stone: Serena sandstone. Mater Struct 2003; 36: 553.

30. Ma T, Inagaki T, Tsuchikawa S. Non-destructive evaluation of wood stiffness and fiber coarseness, derived from SilviScan data, via near infrared hyperspectral imaging. J Near Infrared Spectrosc 2018; 26: 398-405.

31. Faughey GJ, Sharma HSS. A Preliminary Evaluation of near Infrared Spectroscopy for Assessing Physical and Chemical Characteristics of Flax Fibre. J Near Infrared Spectrosc 2000; 8: 61-69.

32. Pornprasit $\mathrm{R}$, Pornprasit $\mathrm{P}$, Boonma $\mathrm{P}$, et al. A study on prediction performance of the mechanical properties of rubber using Fourier-transform near infrared spectroscopy. J Near 
Infrared Spectrosc 2018; 26: 351-358.

33. Lim CH, Sirisomboon P. Near infrared spectroscopy as an alternative method for rapid evaluation of toluene swell of natural rubber latex and its products. J Near Infrared Spectrosc 2018; 26: 159-168.

34. Clark RN, Swayze GA, Wise RA, et al. USGS Digital Spectral Library splib06a. Reston, VA, http://pubs.er.usgs.gov/publication/ds231 (2007).

35. Viscarra Rossel RA, Behrens T, Ben-Dor E, et al. A global spectral library to characterize the world's soil. Earth-Science Rev 2016; 155: 198-230.

36. Ben-Dor E, Ong C, Lau IC. Reflectance measurements of soils in the laboratory: Standards and protocols. Geoderma 2015; 245-246: 112-124.

37. Post JL, Crawford SM. Uses of near-infared spectra for the identification of clay minerals. Appl Clay Sci 2014; 95: 383-387.

38. Ben-Dor, E, Banin A. Near-infrared analysis as a rapid method to simultaneously evaluate several soil properties. Soil Sci Soc Am J 1995; 59: 364-372.

39. Lobell, DB, Asner G. Moisture Effects on Soil Reflectance. Soil Sci Soc Am J 2002; 66: 722-727.

40. Gomez C, Viscarra Rossel RA, McBratney AB. Soil organic carbon prediction by hyperspectral remote sensing and field vis-NIR spectroscopy: An Australian case study. Geoderma 2008; 146: 403-411.

41. Douglas RK, Nawar S, Alamar MC, et al. Rapid prediction of total petroleum hydrocarbons concentration in contaminated soil using vis-NIR spectroscopy and regression techniques. Sci Total Environ 2018; 616-617: 147-155.

42. Ng W, Malone BP, Minasny B. Rapid assessment of petroleum-contaminated soils with infrared spectroscopy. Geoderma 2017; 289: 150-160.

43. Nasser M, Gibson A, Koor N, et al. VIS/NIR Spectroscopy to determine the spatial variation of the weathering degree in Paleogene clay soil-London Clay Formation. In: EGU General Assembly Conference Abstracts. 2017, p. 12700.

44. Viscarra Rossel RA, Walvoort DJJ, McBratney AB, et al. Visible, near infrared, mid infrared or combined diffuse reflectance spectroscopy for simultaneous assessment of various soil properties. Geoderma 2006; 131: 59-75. 
45. Afzal P, Yasrebi AB, Saein LD, et al. Prospecting of Ni mineralization based on geochemical exploration in Iran. J Geochemical Explor 2017; 181: 294-304.

46. Andrews WL, Tardio J, Bhargava SK, et al. Development of a new near infrared (NIR) tool for quantifying coffinite (USiO4) in a moderately complex uranium ore analogue. J Geochemical Explor 2017; 182: 80-93.

47. Magendran T, Sanjeevi S. Hyperion image analysis and linear spectral unmixing to evaluate the grades of iron ores in parts of Noamundi, Eastern India. Int J Appl Earth Obs Geoinf 2014; 26: 413-426.

48. Gallello G, Ghorbani S, Ghorbani S, et al. Non-destructive analytical methods to study the conservation state of Apadana Hall of Persepolis. Sci Total Environ 2016; 544: 291-298.

49. Bassani C, Cavalli RM, Cavalcante F, et al. Deterioration status of asbestos-cement roofing sheets assessed by analyzing hyperspectral data. Remote Sens Environ 2007; 109: 361-378.

50. Gurgurewicz J, Mège $D$, Carrère $V$, et al. Inferring alteration conditions on Mars: Insights from near-infrared spectra of terrestrial basalts altered in cold and hot arid environments. Planet Space Sci 2015; 119: 137-154.

51. Ord A, Hobbs B. Experimental Control of the Water-Weakening Effect in Quartz. In: Hobbs B, Heard H (eds) Mineral and Rock Deformation: Laboratory Studies. American Geophysical Union, 1986.

52. Butcher E, Gibson A, Benson P. Initial development of an NIR strain measurement technique in brittle geo-materials. In: EGU General Assembly Conference Abstracts. 2016, p. 13013.

53. Bieniawski ZT, Hawkes I. Suggested Methods For Determining Tensile Strength of Rock Materials. Int Soc Rock Mech Comm Stand Lab F Tests 1978; 15: 99-103.

54. de Linaje VA, Khan SD. Mapping of diagenetic processes in sandstones using imaging spectroscopy: A case study of the Utrillas Formation, Burgos, Spain. Sediment Geol 2017; 353: 114-124.

55. Clark RN, King TV V, Klejwa M, et al. High spectral resolution reflectance spectroscopy of minerals. J Geophys Res Solid Earth 1990; 95: 12653-12680.

56. Murphy RJ, Monteiro ST. Mapping the distribution of ferric iron minerals on a vertical mine face using derivative analysis of hyperspectral imagery (430-970nm). ISPRS J Photogramm Remote Sens 2013; 75: 29-39. 
57. Crowley JK. Visible and near-infrared spectra of carbonate rocks: Reflectance variations related to petrographic texture and impurities. J Geophys Res Solid Earth 1986; 91: 50015012.

58. Gaffey SJ. Spectral reflectance of carbonate minerals in the visible and near infrared (0.352.55 um): Anhydrous carbonate minerals. J Geophys Res Solid Earth 1987; 92: 1429-1440. 

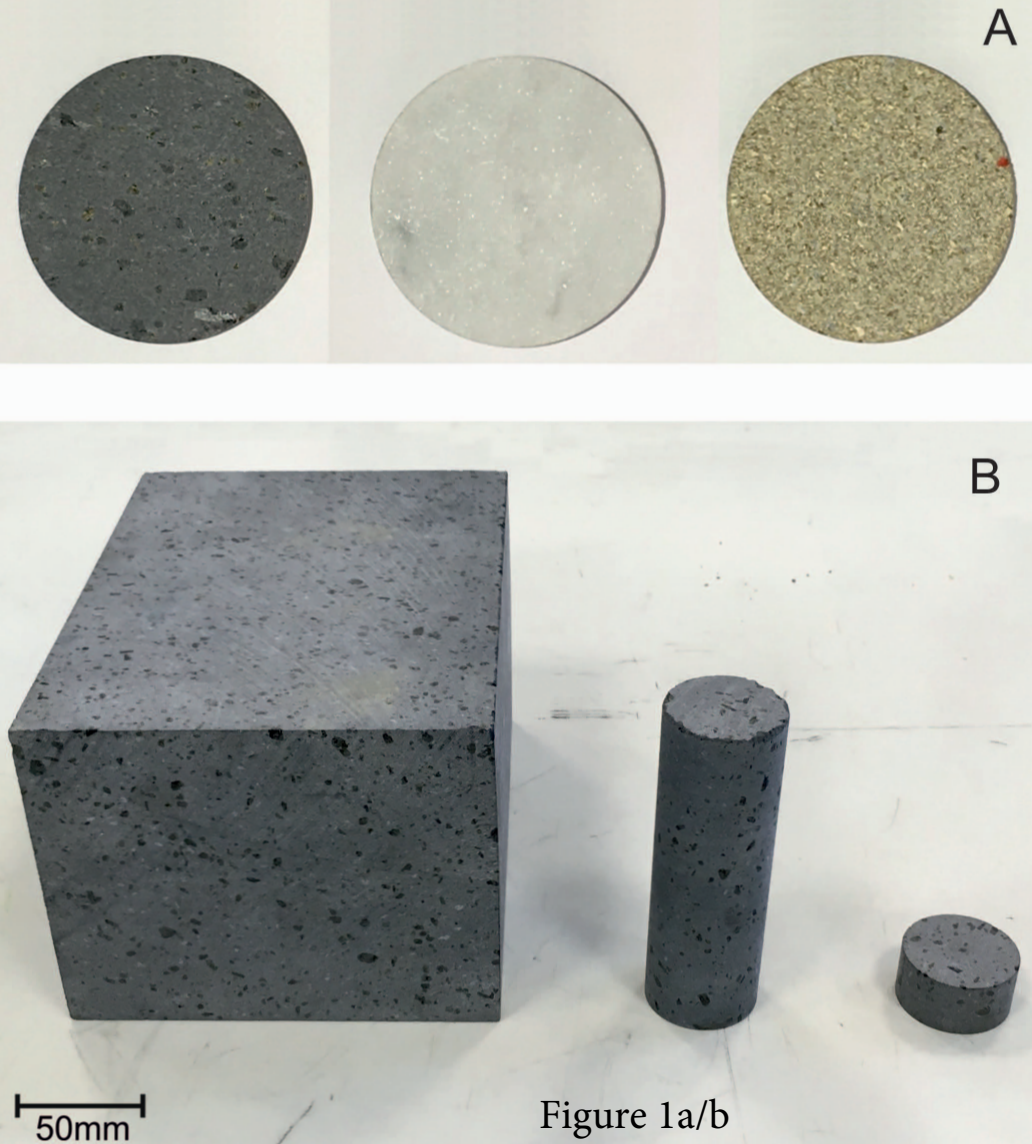

Figure $1 \mathrm{a} / \mathrm{b}$ 


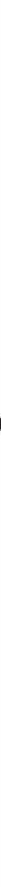




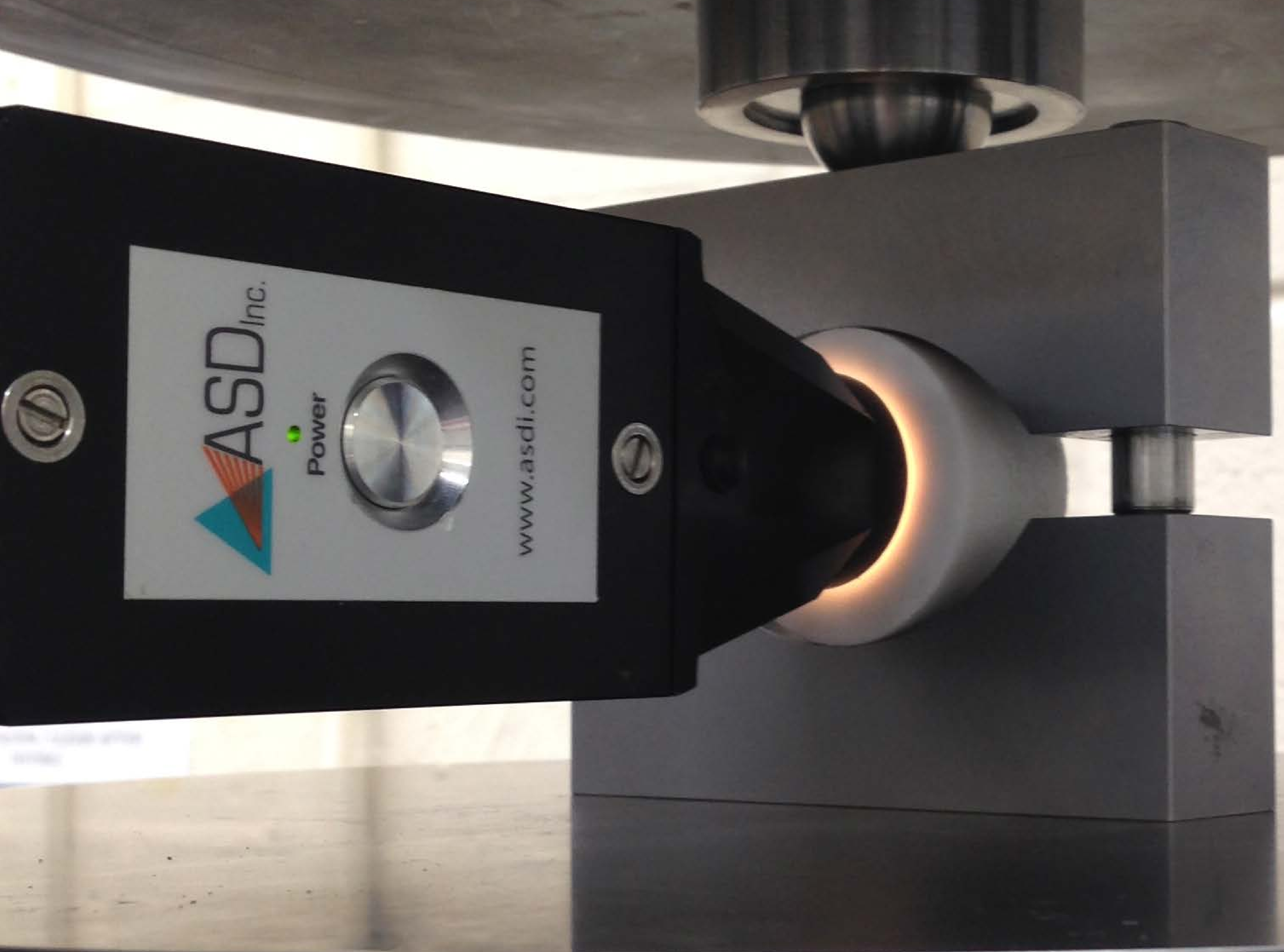


Figure 4

$\left\{\begin{array}{l}6.24 \\ 5.68\end{array}\right.$

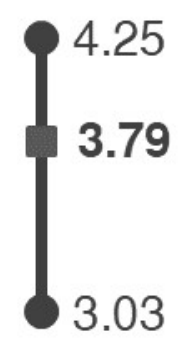

5.4

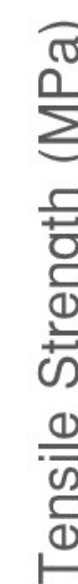

3.25

3.03

2 


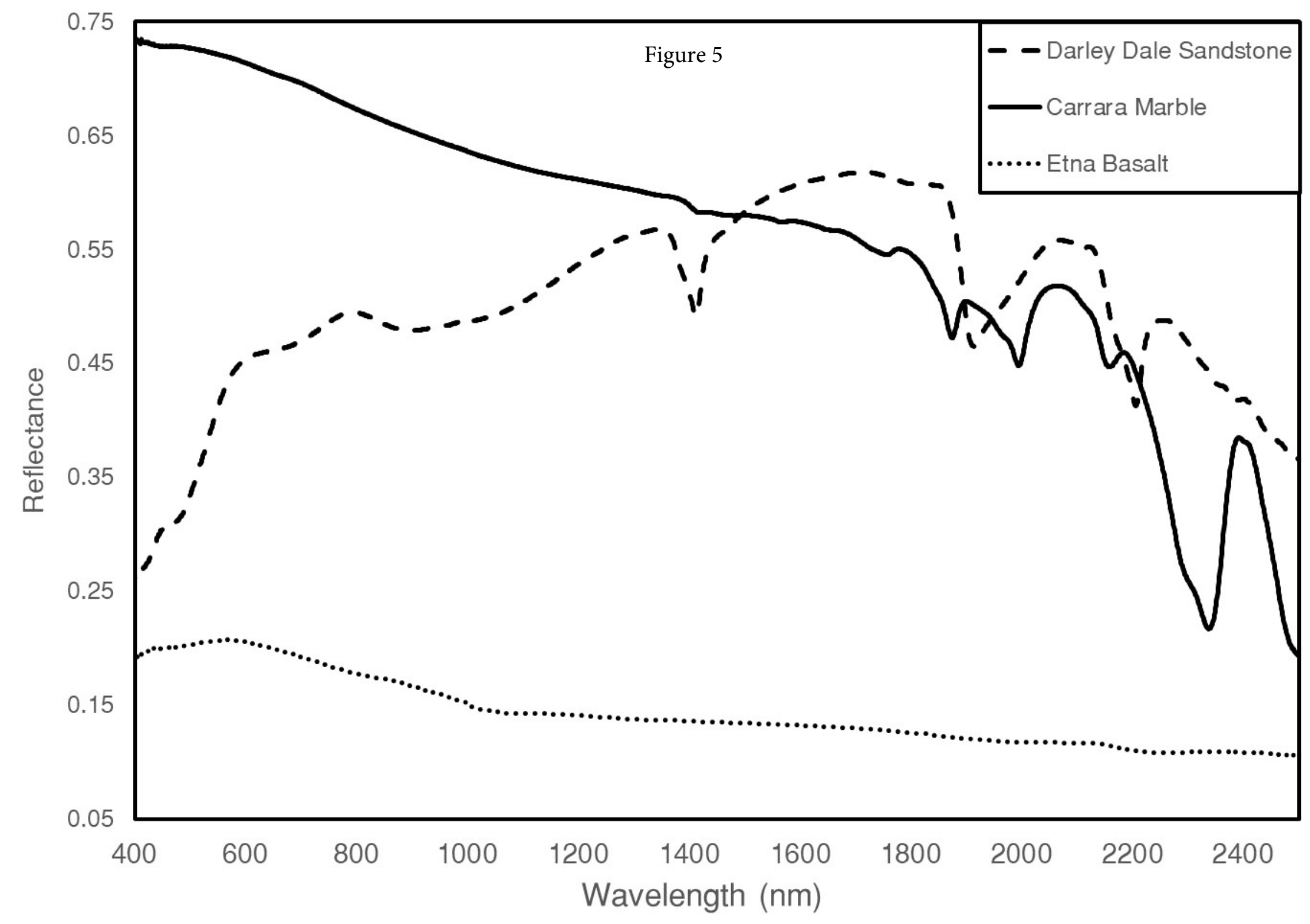




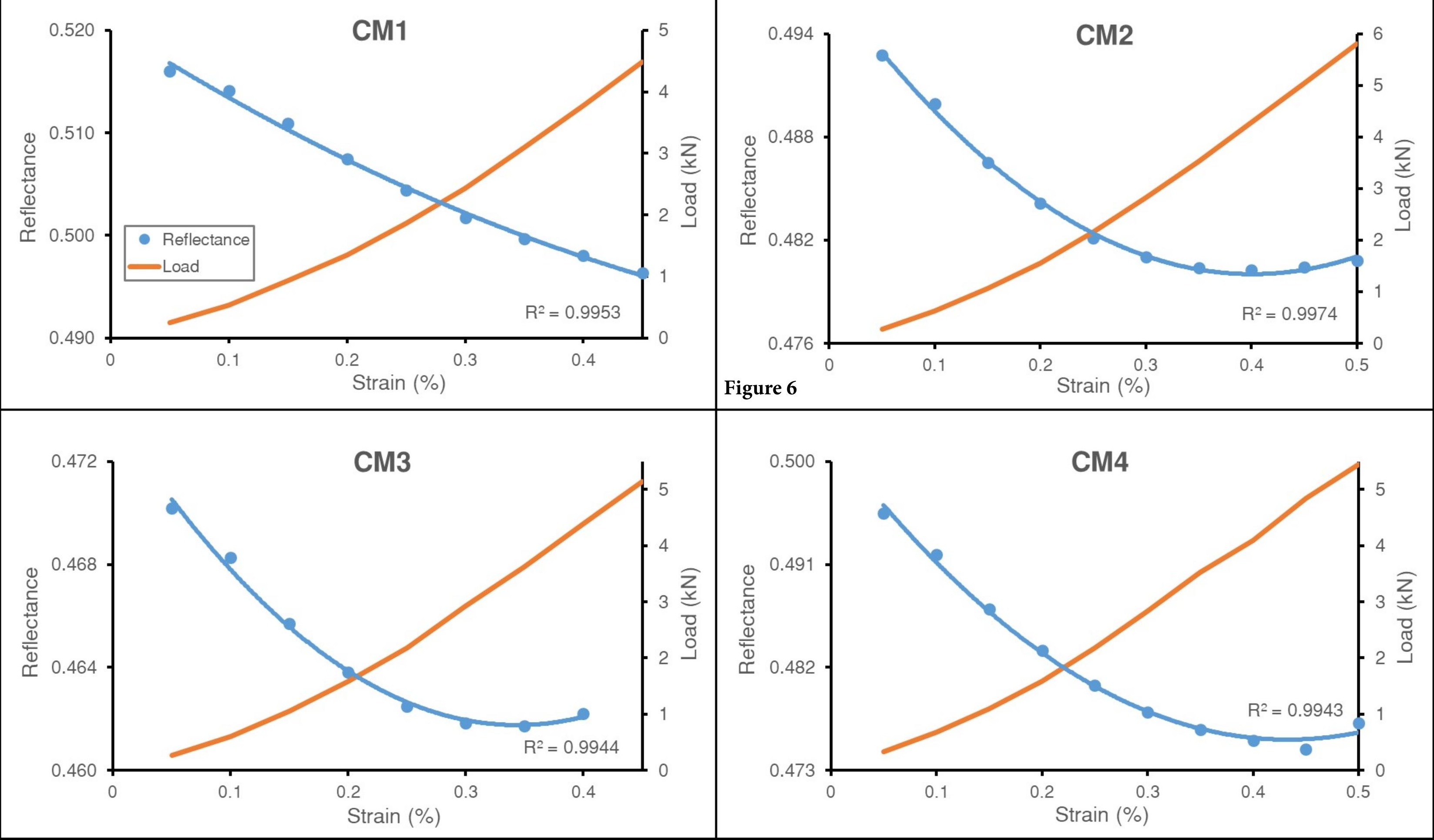




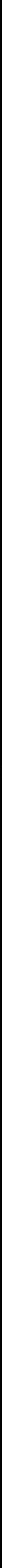




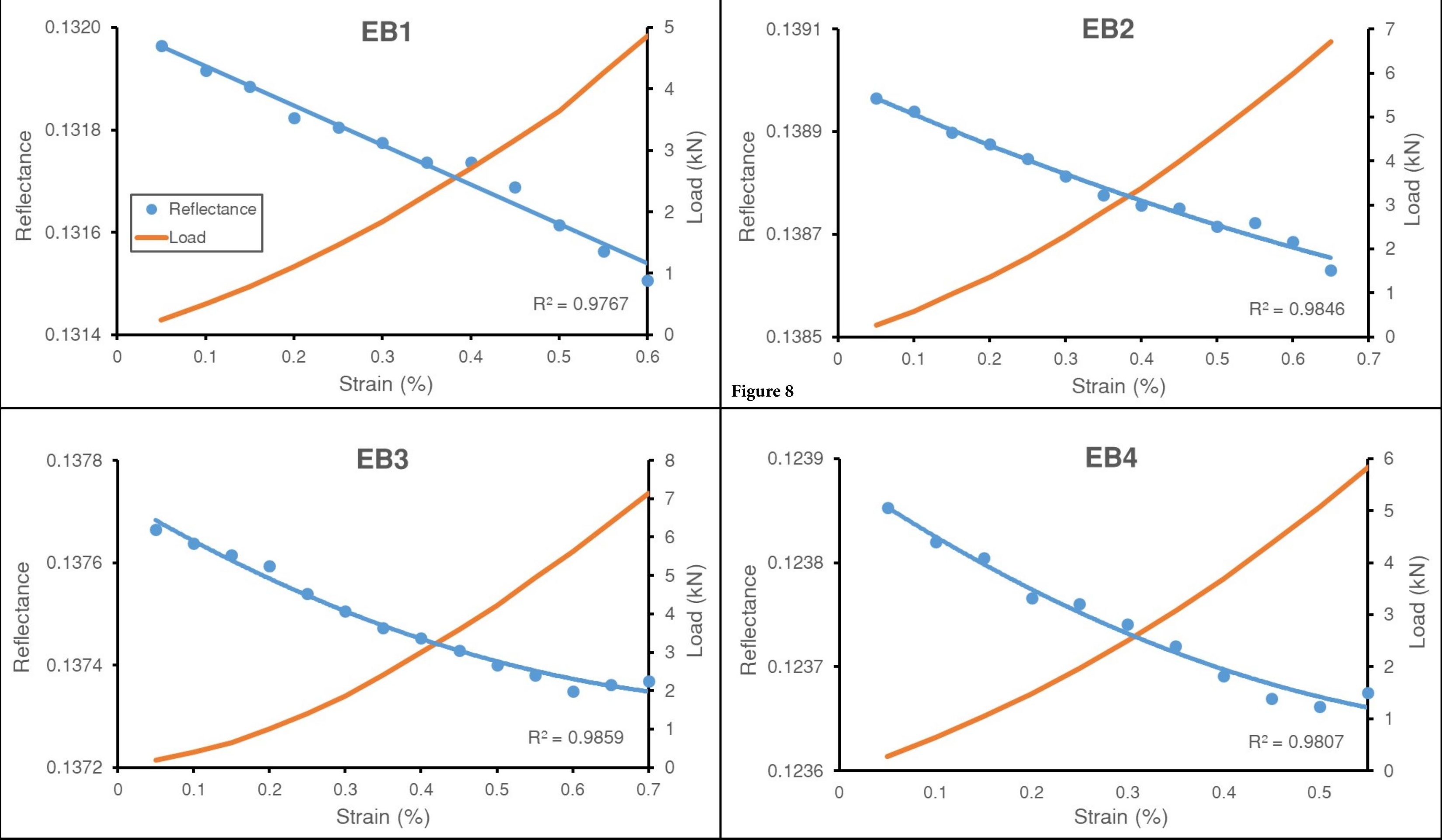




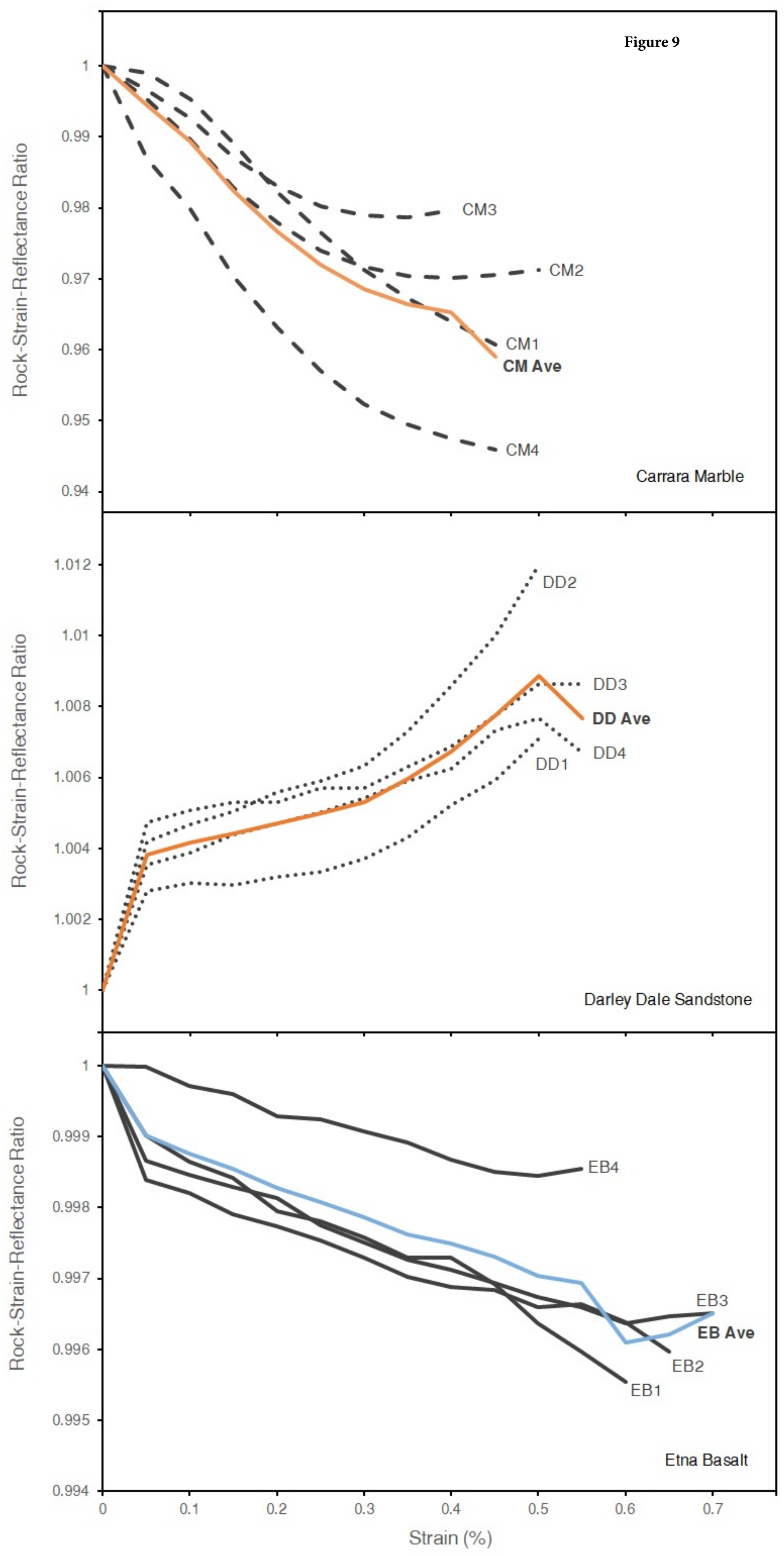

